\title{
Inflectional Morphology in Fluent Aphasia: A Case Study in a Highly Inflected Language
}

\author{
Noémie Auclair-Ouellet
}

McGill University, Canada

\section{Pauline Pythoud}

Université de Neuchâtel, Switzerland

\section{Monica Koenig-Bruhin \\ Luzerner Kantonsspital, Switzerland}

\section{Marion Fossard}

Université de Neuchâtel, Switzerland

\begin{abstract}
Inflectional morphology difficulties are typically reported in non-fluent aphasia with agrammatism, but a growing number of studies show that they can also be present in fluent aphasia. In agrammatism, morphological difficulties are conceived as the consequence of impaired phonological encoding and would affect regular verbs more than irregular verbs. However, studies show that inflectional morphology difficulties concern both regular and irregular verbs, and that their origin could be more conceptual/semantic in nature. Additionally, studies report more pronounced impairments for the processing of the past tense compared to other tenses. The goal of this study was to characterize the impairment of inflectional morphology in fluent aphasia. RY, a 69-year-old man with chronic fluent aphasia completed a short neuropsychological and language battery and three experimental tasks of inflectional morphology. The tasks assessed the capacity to select the correct inflected form of a verb based on time information, to access the time information included in an inflectional morpheme, and to produce verbs with tense inflection. His performance was compared to a group of five adults without language impairments. Results showed that RY had difficulties selecting the correct inflected form of a verb, accessing time information transmitted by inflectional morphemes, and producing inflected verbs. His difficulties affected both regular and irregular verbs, and verbs in the present, past, and future tenses. The performance also shows
\end{abstract}

\section{Corresponding author:}

Noémie Auclair-Ouellet, School of Communication Sciences and Disorders, Faculty of Medicine, McGill University, 200 I McGill College, room 820, Montreal, QC H3A IGI, Canada.

Email: noemie.auclairouellet@mcgill.ca 
the influence of processing limitations over the production and comprehension of inflectional morphology. More studies of inflectional morphology in fluent aphasia are needed to understand the origin of difficulties.

\section{Keywords}

Inflectional morphology, fluent aphasia, paragrammatism, tense

\section{Introduction}

Agrammatism is an acquired disorder of grammar processing that is associated with non-fluent language profiles. According to the Declarative/Procedural Model (DPM) (Ullman, 2001), in agrammatism, inflection of regular verbs (which are formed by rule application) is impaired, but inflection of irregular verbs (which are retrieved in the lexicon) is largely spared. However, studies show that this dissociation of performance is not systematic and that regular and irregular verbs are both susceptible to impairment in agrammatism (Faroqi-Shah, 2007). To account for impairments that affect both regular and irregular verbs, Faroqi-Shah and Thompson proposed the Diacritical Encoding and Retrieval (DER) hypothesis (Faroqi-Shah \&Thompson, 2003, 2004, 2007; see also Faroqi-Shah \& Friedman, 2015). The DER hypothesis is an adaptation of Levelt's model of language production (Levelt, 1989). According to Levelt (1989), morphological difficulties are attributable to an impairment at the stage of phonological encoding. Because regular verbs are formed by assembling morphemes through rule application, they are more vulnerable to defects at the stage of phonological encoding than irregular verbs that are directly retrieved in the lexicon. Instead of locating the origin of morphological difficulties at the step of phonological encoding, Faroqi-Shah and Thompson $(2003,2004,2007)$ propose that they are caused by impairments at the level of diacritical features. Diacritical features are pieces of grammatical information that need to be specified in order for the correct morphological form to be selected. Diacritical features would constitute an interface between semantic/conceptual information such as time, number, etc., and their tangible realization as morphemes. Since the step of diacritical features occurs at the prephonological stage, its impairment has similar consequences on both regular and irregular verbs. Consequently, according to the DER hypothesis, patients should have difficulties inflecting both regular and irregular verbs.

Faroqi-Shah and Thompson $(2003,2004,2007)$ showed that patients with agrammatism had difficulties with both regular and irregular verbs. In production tasks, patients tended to make substitution errors, which are consistent with difficulties selecting the correct inflected form, not with general lexical-retrieval impairments or deficits at the phonological encoding stage of word production. More recently, Faroqi-Shah and Friedman (2015) conducted a meta-analysis that focused on the production of tense in aphasia. Compared to other forms of inflectional markings (e.g., for aspect, mode, and person), tense is particularly difficult to produce for patients with agrammatism. In order to explain this phenomenon, models focusing on tense in inflectional morphology have emerged, including the DER. Another model has proposed a selective impairment of the past tense in aphasia (Bastiaanse, 2013). According to the Past Discourse Linking Hypothesis (PADILIH), events in the past tense are harder to describe because they require establishing links with previous events within the discourse. Consequently, the production of past tense marking in morphology is also more demanding (Bastiaanse, 2013). The meta-analysis of Faroqi-Shah and Friedman showed more difficulties for the production of verbs that required tense marking compared to non-finite verbs. However, contrary to their prediction and the PADILIH, there was no systematic significant 
difference between the past, present, and future tenses, although the past was more impaired than the present tense and future tense in one of the tasks (sentence production priming). This task was not the most cognitively demanding, showing that there is no direct relationship between task difficulty and selective impairment for the past tense. Nevertheless, the authors observed an overall influence of task demand with performances being poorer overall in more demanding tasks.

Because they observed differences in performance between different tasks that put different levels of demand on performance, Faroqi-Shah and Friedman (2015) concluded that processing demands would play an important role in difficulties. Accounts of the impact of processing demands over inflectional morphology in aphasia are scarce (but see Kok, van Doorn, \& Kolk, 2007), but studies of patients with Parkinson's disease (PD) are consistent with this idea (Colman, Koerts, van Beilen, Leenders, Post \& Bastiaanse, 2009; Macoir, Fossard, Mérette, Langlois, Chantal, \& Auclair-Ouellet, 2013). According to the DPM, PD patients are expected to have a profile similar to that of patients with agrammatism (impaired inflection of regular verbs but spared inflection of irregular verbs). Several studies conducted with non-demented PD patients have not produced the dissociation of performance predicted by the DPM (Colman et al., 2009; Macoir et al., 2013; Longworth, Keenan, Barker, Marslen-Wilson, \& Tyler, 2005; Penke, Janssen, Indefrey, \& Seitz, 2005), and some have proposed that inflectional difficulties were related to the executive deficit that is characteristic of this disease (Colman et al., 2009; Macoir et al., 2013). According to Colman et al. (2009), dopaminergic dysfunction disrupts well-learned and automatic language and cognitive processes, including verb inflection. Consequently, inflecting verbs correctly requires more executive and working memory resources. Since these resources are limited in PD, patients are vulnerable to processing overload and make more errors in both regular and irregular verb inflection.

Another line of research shows that grammatical impairments are not exclusively found in nonfluent profiles. Studies of paragrammatism show grammatical impairment characterized by altered sentence structure, aborted sentences, and errors of morphology in patients with otherwise fluent profiles (Bastiaanse, 2011; Butterworth \& Howard, 1987; Edwards, 2005). The DPM (Ullman, 2001) proposed that people with fluent language impairment have difficulties for irregular verbs but largely spared performance for regular verbs, which constitutes the opposite of the typical performance of non-fluent patients. However, a recent study of paragrammatism revealed difficulties that were not related to regularity but that seemed to find their origins in producing words that have rich and complex semantic content, such as inflected verbs (Bastiaanse, 2011).

Agrammatism has received more attention than paragrammatism, but there is growing evidence that morphological difficulties are found in both fluent and non-fluent profiles. Different lines of research point to difficulties at the grammatical/semantic interface and to the influence of processing demands in morphological impairment (Faroqi-Shah \& Friedman, 2015). This study reports the performance of RY, a Swiss-German-speaking man with fluent aphasia. RY completed three tasks of morphology and a language and neuropsychological battery. The study aimed to compare his performance for regular and irregular verbs and to determine if it was characterized by a dissociation, as predicted by dualistic models such as the DPM (Ullman, 2001), or by relatively equivalent performances, as predicted by the DER (Faroqi-Shah \& Thompson, 2003, 2004, 2007). Following the DER hypothesis, the tasks focused on tense inflection and the activation of tense diacritical features to unveil their involvement in morphological difficulties. They also allowed for a comparison of the past tense to the present and the future tense to explore the presence of a marked disadvantage for the production and comprehension of the past tense in fluent aphasia, a result that would be predicted by the PADILIH (Bastiaanse, 2013). Lastly, the study included measures of working memory and executive function to explore the relationship between processing demands and morphological difficulties. Decreased processing resources (e.g., impaired working memory 
and executive functions) would cause impairments of both regular and irregular verb inflection (Colman et al., 2009). Qualitative aspects of performance suggestive of executive impairment, such as perseverations, would also be compatible with an influence of decreased processing resources.

This study has implications for the clinical assessment of morphology and cognitive deficits in patients with fluent aphasia. It informs the development of inflectional morphology tasks and the selection of complementary language and cognitive tasks to understand the origins of difficulties.

\section{Methods}

\section{I Participants}

RY is a 69-year-old man with a university degree who suffered a stroke of the left middle cerebral artery that caused temporo-parietal lesions four years before he was involved in the present study. RY's native language and the one he used most often before the stroke is Swiss-German. Before the stroke, he was also fluent in French and Italian.

Swiss-German is the spoken everyday language in the German part of Switzerland, whereas standard German is used for writing. Being an oral language, Swiss-German is subject to regional variation. In order to keep the performance comparable between RY and the control group, experimental tasks were conducted in the written modality in standard German. The written modality is usually considered more demanding, but RY had better written comprehension than oral comprehension.

In the initial medical report, RY received a diagnosis of Wernicke's aphasia. He had severely impaired comprehension, word-retrieval difficulties, and impaired repetition. By the time the study started, 4 years later, his aphasia had partly recovered and his profile was broadly consistent with conduction aphasia. The Token Test from the Aachener Aphasie Test (AAT) (Huber, Poeck, Weniger, \& Willmes, 1983) showed a moderate comprehension deficit (age-corrected error score =32). The repetition of long words and sentences was still impaired (AAT: long words = 24/30; sentences $=16 / 30)$. In conversation, RY still presented comprehension deficits, and word-finding deficits with semantic and phonological paraphasias and "conduite d'approche." He also presented with paragrammatism characterized by impaired inflectional morphology, aborted sentences and mixed sentence structures.

RY's scores in the experimental tasks were compared to those of five age-matched and education-matched men without language or cognitive impairment. All participants from the control group were native speakers of Swiss-German. They completed all the tests from the language battery because some of the tasks were adapted from existing tasks (i.e., the written sentence production test and the verb naming test) and did not have norms (see Table 1).

Table 1 gives RY's raw scores and the control group's raw scores on the neuropsychological and language battery. The scores of the control participants on the Montreal Cognitive Assessment ((MoCA) Nasreddine et al., 2005), a short screening test of global cognition, were all within the normal range (26 and higher). RY presented some cognitive impairment (MoCA = 17/30). Furthermore, his performance in a short executive function screening test (Frontal Assessment Battery (FAB), Dubois, Slachevsky, Litvan, \& Pillon, 2000) test showed executive impairment (RY: $13 / 18$; control mean in Dubois et al. $(2000)=17.3 / 18$, standard deviation $(S D)=0.8)$, and his performance in digit span showed impaired short-term and working memory (Wechsler, 1987).

RY's performance in non-verbal semantic picture-matching was preserved both for objects (Pyramids and Palm Trees Test: Howard \& Patterson, 1992) and actions (Kissing and Dancing Test: Bak \& Hodges, 2003). His scores in oral and written comprehension of sentences ((AAT) 
Table I. Neuropsychological and language battery.

\begin{tabular}{lcc}
\hline & RY & Control group \\
\cline { 2 - 3 } & & Mean (standard deviation) \\
\hline Age & 69 & $69.4(3.78)$ \\
MoCA & 17 & $28.6(1.34)$ \\
FAB (I8) & 13 & - \\
Digit span forward & 4 & - \\
Digit span backward & 3 & - \\
KDT (52) & 48 & $48.4(2.19)$ \\
PPTT (52) & 52 & $51(1)$ \\
Semantic fluency (animals, I minute) & 12 & $22.8(6.06)$ \\
Oral verb naming (32) & 19 & $31(0.71)$ \\
Oral comprehension of sentences, AAT (30) & 13 & $28.4(1.14)$ \\
Oral comprehension of sentences, BIAS (6) & 3 & $6(0)$ \\
Written comprehension of sentences, AAT (30) & 22 & $26(2.55)$ \\
Written sentence production (30) & 15 & $29.6(0.55)$ \\
Writing words and sentences to dictation, AAT (30) & 23 & $29.2(0.45)$ \\
\hline
\end{tabular}

Notes: AAT: Aachener Aphasie Test; BIAS: Bielefelder Aphasie Screening; FAB: Frontal Assessment Battery; KDT: Kissing and Dancing Test; MoCA: Montreal Cognitive Assessment; PPTT: Pyramids and Palm Trees Test.

Huber et al., 1983; Bielefelder Aphasie Screening: Richter, Wittler, \& Hielscher-Fasabend, 2006) showed impairments. RY had significant difficulties understanding relative and passive sentences, reversible sentences, and plural marking. These difficulties were more marked in oral than in written comprehension. His written production of words and sentences in the AAT writing to dictation subtest was impaired. Compared to the participants of the control group, he also had a poorer performance in a written sentence production test adapted from the AAT oral verb naming test (RY: $15 / 30$; control mean $=29.6, S D=0.55$ ). His performance in semantic fluency (Consortium to Establish a Registry for Alzheimer's Disease-German: Ehrensperger, Berres, Taylor, \& Monsch, 2010) was impaired according to tests' norms and was lower than the control group's average score. RY's verb naming score (De Bleser \& Kauschke, 2003) was lower than the control group's average score (RY: 19/32; control mean $=31, S D=0.71)$.

\subsection{Material and procedure}

The participants completed three experimental tasks similar to those described by Faroqi-Shah and Thompson (2003, 2004, 2007).

2.2.I Inflected verb choice. In this task, participants chose an inflected verb to complete a carrier phrase that started with a time adverb. A verb in the infinitive (e.g., lachen (laugh)) was presented followed by a time adverb and three inflected forms of this verb (in the past (Präteritum), present, and future tenses) (e.g., Gestern... wird er lachen-lachte er-lacht er; Yesterday... he will laugh - he laughed - he laughs). The participant had to choose the correct form of the verb, based on the adverb included in the carrier phrase (in bold in the example).

The task included 72 verbs. All the verbs had a frequency ranging from 10 to 85 occurrences per million words (mean $(M)=41.24 ; S D=2.58$ ) (Baayen, Piepenbrock, \& Gulikers, 1995). They were all transitive, had no more than three syllables in all their inflected forms, and contained no 
separable particles. Half of the verbs were regular and half were irregular. Frequency was not different between regular and irregular verbs, $t(70)=0.016, p=.987$. For regular verbs, the 36 items were subdivided equally to target the past, the present, and the future. The frequency of verbs was equivalent for the three tenses, $F(2,33)=0.001, p=.999$. Since the future is formed with an auxiliary and the verb in the infinitive in German, and consequently the irregularity of verbs is not manifested in the future tense, half of the irregular items targeted the past and half targeted the present tense. The frequency of verbs was equivalent for items targeting the present and the past tense, $t(34)=1.544, p=.132$. The distractor in the future tense was still given as a response choice for these items to keep the demands of the task comparable between the regular and irregular items. The items were presented in semi-random order.

This task assessed the participants' capacity to activate the appropriate tense feature and, based on it, to select the correct inflected form of the verb. Providing choices reduced lexical demands. To ensure that RY had a good comprehension of time adverbs, he was asked to point at Gestern (yesterday), Jetzt (now), and Morgen (tomorrow) on a calendar prior to completing the experimental tasks.

2.2.2 Time adverb choice. In this task, participants chose which time adverb (Gestern (yesterday), Jetzt (now), and Morgen (tomorrow)) completed a sentence that included an inflected verb. The verbs were the same as in the first task and their subdivision according to regularity and target time was the same.

The second task assessed the opposite process as the first task. Based on an inflected verb, participants had to activate the appropriate tense feature (which gave access to related conceptual time information) and choose the appropriate time adverb.

2.2.3 Inflected verb production. In this task, participants had to write an inflected verb to complete a carrier phrase. First, a verb in the infinitive (e.g., zeichnen (draw)) and the third person singular pronoun (er) were presented. Then, a time adverb was presented and the participant had to complete the sentence correctly. Because of the "verb-second" rule of German, correct answers had the following structures: "adverb-verb-pronoun" for the past (e.g., Gestern zeichnete er) and the present tense (e.g., Jetzt zeichnet er) and "adverb-auxiliary-pronoun-verb" for the future tense (e.g., Morgen wird er zeichnen).

The task included 36 different verbs that were not used in the inflected verb choice task. The frequency of verbs ranging from 14 to 80 occurrences per million words $(M=41.22 ; S D=3.64)$ (Baayen et al., 1995). The subdivision of items according to regularity and tense was similar to that of the two first tasks. Frequency was equivalent between regular and irregular verbs, $t(34)=0.015$, $p=.988$, between regular verbs in the three tenses, $F(2,15)=0.002, p=.998$, and between irregular verbs in the present and the past tense, $t(16)=1.097, p=.289$.

This task assessed the participants' capacity to activate tense features, select the correct form of the verb, and produce it in the absence of lexical support. This task is of a higher level of difficulty than the two first ones but the use of the written modality reduced short term and working memory demands.

\section{Results}

Table 2 presents the results for RY and the control group in the three experimental tasks.

In the inflected verb choice task, RY had a score of 59/72 (81.94\%). All the control participants had a perfect score. For regular verbs, RY had a score of 32/36 (88.89\%). For irregular verbs, his score was $27 / 36(75 \%)$. He had a better score for verbs in the present tense $(27 / 30,90 \%)$ than verbs 
Table 2. Number of correct answers in the experimental tasks.

\begin{tabular}{|c|c|c|c|c|c|c|c|}
\hline & & \multicolumn{3}{|c|}{ Regular verbs } & \multicolumn{2}{|c|}{ Irregular verbs } & \multirow[t]{2}{*}{ Total } \\
\hline & & Past & Present & Future & Past & Present & \\
\hline \multirow{3}{*}{$\begin{array}{l}\text { Inflected verb } \\
\text { choice }\end{array}$} & RY & 12 & II & 9 & II & 16 & 59 \\
\hline & $\begin{array}{l}\text { Control group: } \\
\text { mean (standard } \\
\text { deviation }(S D) \text { ) }\end{array}$ & $12(0)$ & $12(0)$ & $12(0)$ & $18(0)$ & $18(0)$ & $72(0)$ \\
\hline & Number of items & 12 & 12 & 12 & 18 & 18 & 72 \\
\hline \multirow{3}{*}{$\begin{array}{l}\text { Time adverb } \\
\text { choice }\end{array}$} & RY & 9 & 7 & 9 & 4 & 16 & 45 \\
\hline & $\begin{array}{l}\text { Control group: } \\
\text { mean (SD) }\end{array}$ & $12(0)$ & $12(0)$ & $12(0)$ & $18(0)$ & I $7.8(0.45)$ & $71.8(0.45)$ \\
\hline & Number of items & 12 & 12 & 12 & 18 & 18 & 72 \\
\hline \multirow{3}{*}{$\begin{array}{l}\text { Inflected verb } \\
\text { production }\end{array}$} & RY & 6 & 3 & 2 & 0 & 0 & II \\
\hline & $\begin{array}{l}\text { Control group: } \\
\text { mean }(S D)\end{array}$ & $6(0)$ & $5.6(0.55)$ & $5.6(0.55)$ & $8.6(0.55)$ & $8.6(0.55)$ & $34.8(0.84)$ \\
\hline & Number of items & 6 & 6 & 6 & 9 & 9 & 36 \\
\hline
\end{tabular}

in the past tense $(23 / 30,76.67 \%)$. All of RY's seven errors for irregular verbs in the past tense were selections of the present tense. All three errors for verbs in the present tense were selections of the past tense. For errors in items that targeted the future tense, RY chose the past tense twice and the present tense once.

In the time adverb choice task, RY obtained a score of 45/72 (62.5\% correct). Participants of the control group had a score of $71.8 / 72(99.72 \%)$ on average $(S D=0.45)$. RY had $25 / 36(69.44 \%$ correct) for regular verbs and 20/36 (55.56\%) for irregular verbs. RY's performance is comparable between the three tenses for regular verbs (past: $9 / 12,75 \%$; present: $7 / 12,58.33 \%$; and future: $9 / 12,75 \%)$ However, his score is particularly low for irregular verbs in the past tense $(4 / 18,22.22 \%$ correct) compared to irregular verbs in the present tense $(16 / 18,88.89 \%)$. Twelve out of RY's 14 errors for irregular verbs in the past tense were caused by choosing the adverb associated with the present tense.

As expected, RY's performance was most impaired in the inflected verb production task. He obtained a score of 11/36 (30.56\%). The control group had a score of 34.8/36 (96.67\%) on average $(S D=0.84)$. RY did not inflect any of the irregular verbs correctly, both in the past tense and the present tense. In comparison, he had no difficulty for regular verbs in the past tense $(6 / 6,100 \%)$, he inflected correctly half of the regular verbs in the present tense $(3 / 6,50 \%)$, and one-third of the regular verbs in the future tense $(2 / 6,33.33 \%)$. For irregular verbs in the past tense, six out of his nine errors are regularizations (*schwimmte instead of schwamm (swam)), one is a past participle, one is a neologism, and one is a past participle formed with a neologism. For irregular verbs in the present tense, five out of his nine errors are regularizations (*vertragt instead of verträgt (tolerate)), two are infinitives, one is a substitution for another verb in the present tense and one is a substitution for the same verb in the present tense. For regular verbs, six out of his seven errors are substitutions of the present and the future by the past tense. The remaining error is an incorrect passive construction. RY's errors for regular verbs in the future tense are three substitutions for the past tense and one incorrect passive construction. The three errors for regular verbs in the present tense are all productions of the past tense. 


\section{Discussion}

RY, a 69-year-old man with chronic fluent aphasia had difficulties selecting the correct inflected form of a verb, accessing time information transmitted by inflectional morphemes, and producing inflected verbs. The results show that patients with fluent aphasia can present important difficulties of inflectional morphology. RY is more impaired in irregular than regular verb inflection and produces several regularization errors. However, his performance for regular verbs in the production and forced-choice tasks is not preserved and he makes substitution errors in the production task. These results are not easily explained within the framework of dualistic models (Ullman, 2001).

Results are compatible with the DER hypothesis (Faroqi-Shah \&Thompson, 2003, 2004, 2007), which proposes that inflectional morphology difficulties are caused by an impairment at the diacritical feature level. However, the precise origin of difficulties (activation of the diacritical features from the conceptual level, or selection of the morphological form from the diacritical features) cannot be easily determined based on performance. There are some qualitative aspects of performance that show that semantic information is accessible but is difficult to transmit in the correct morphological form. For example, RY produces past tense marking, although incorrectly, in a majority of his responses for irregular past tense items in the inflected verb production task. Results do not show a clear disadvantage for past tense inflection compared to other tenses. In fact, for regular verbs, the past tense is either as preserved (Time Adverb Choice) or even better preserved (Inflected Verb Choice and Inflected Verb Production) than the present tense and the future tense. Because of the small number of items, results must be interpreted with caution but the global trend does not support a clear disadvantage for the past tense.

In summary, the results are consistent with meta-analyses of inflectional morphology in patients with aphasia (Faroqi-Shah, 2007; Faroqi-Shah \& Friedman, 2015) that show that performance in inflectional morphology is complex and cannot be summarized in terms of dissociations between regular and irregular verbs, and between the past tense versus other tenses. Like the study of Faroqi-Shah and Friedman (2015), this study suggests an impact of processing demands over performance. However, this impact would not only be manifested by more pronounced difficulties in more demanding tasks (e.g., Inflected Verb Production) but also across different tasks, due to the inherent demands of inflectional morphology. In fact, Faroqi-Shah and Friedman (2015) observed that in a study that systematically manipulated the level of difficulty of inflectional morphology tasks (Kok et al., 2007), the effect of task difficulty was not seen in all patients. This is more compatible with an influence of individual processing resources over performance rather than a general influence of task difficulty. As will be further explained below, RY's results in the neuropsychological battery and the qualitative analysis of his answers in the inflectional morphology tasks further clarify the origin of his difficulties.

RY has preserved non-verbal semantic cognition for objects and actions, which suggests that a central semantic impairment that affects time concepts is not likely the cause of his difficulties. His basic understanding of temporal adverbs involved in the tasks is also preserved as he is able to identify yesterday, now, and tomorrow on the calendar. However, his scores in semantic fluency, working memory and the FAB (Dubois et al., 2000) show impairments. These results indicate the presence of processing limitations that can have broad impacts on language. As expected, RY is most impaired in the production task, which is presumably the most demanding. However, he also has important difficulties in the forced-choice tasks.

On the inflected verb choice task, all the errors for irregular verbs in the past tense were selections of the present tense form. Interestingly, the present tense form is very similar to what the past tense would be if it was regular. For example, the third person singular of the Präteritum (past tense) for the verb "vergleichen" (compare) is "verglich." If this verb followed the regular 
inflection pattern, the past tense form would be "*vergleichte," which is very similar to "vergleicht," the correct present tense form. In other words, RY chose an inflected verb that presented characteristics that were more compatible with the regular present tense pattern of inflection rather than the correct past tense form. This pattern is found in several irregular verbs in German. Also, in the inflected verb production task, RY produced many regularization errors for irregular verbs in the past tense and, interestingly, the majority of his errors for regular verbs are substitutions of the present tense and future tense forms for the regular past tense form in "-te." This suggests a form of perseveration over the regular past tense inflectional pattern which is incompatible with specific difficulties to understand and produce the past tense form. However, this is consistent with the conclusions of Faroqi-Shah and Friedman (2015) who suggest that individual variability could be explained by the use of different processing strategies, and that "when faced with the challenge of transitioning from semantic representations to morphosyntactic representations, the agrammatic system resorts to using the most accessible elements". It is important to note that cognitive demands can be increased by manipulating a task's design (Faroqi-Shah \& Friedman, 2015), but that the production and comprehension of inflected verbs remains an inherently demanding aspect of language. This is in line with previous studies of patients with Parkinson's disease (Colman et al., 2009; Macoir et al., 2013).

This study as well as others (Bastiaanse, 2011; Butterworth \& Howard, 1987; Edwards, 2005) encourages clinicians to assess morphology in both non-fluent and fluent aphasia profiles. Even though impaired inflectional morphology is strongly associated with agrammatism, important difficulties can also be found in patients who have an overall fluent profile. These difficulties have an important impact over functional communication. Performance is influenced by regularity and tense, but also by the patients' processing capacities and resources. A more thorough consideration of the impact of cognitive impairment over language (Martin \& Reilly, 2012; Murray \& Ramage, 2000 ) is needed to help clinicians determine ways to support performance during treatment, and to design treatments that promote generalization to everyday interactions.

\section{Funding}

This research received no specific grant from any funding agency in the public, commercial, or not-for-profit sectors.

\section{References}

Baayen, R. H., Piepenbrock, R., \& Gulikers, L. (1995). The CELEX lexical database (WebCelex). Philadelphia, PA: University of Pennsylvania, Linguistic Data Consortium. Available at: http://celex.mpi.nl/ (accessed 15 March 2018).

Bak, T. H., \& Hodges, J. R. (2003). Kissing and dancing - a test to distinguish the lexical and conceptual contributions to noun/verb and action/object dissociation. Preliminary results in patients with frontotemporal dementia. Journal of Neurolinguistics, 16(2), 169-181.

Bastiaanse, R. (2011). The retrieval and inflection of verbs in the spontaneous speech of fluent aphasic speakers. Journal of Neurolinguistics, 24(2), 163-172.

Bastiaanse, R. (2013). Why reference to the past is difficult for agrammatic speakers. Clinical Linguistics \& Phonetics, 27(4), 244-263.

Butterworth, B., \& Howard, D. (1987). Paragrammatisms. Cognition, 26(1), 1-37.

Colman, K. S. F., Koerts, J., van Beilen, M., Leenders, K.L., Post, W.J., \& Bastiaanse, R. (2009). The impact of executive functions on verb production in patients with Parkinson's disease. Cortex, 45(8), 930-942.

De Bleser, R., \& Kauschke, C. (2003). Acquisition and loss of nouns and verbs: Parallel or divergent patterns? Journal of Neurolinguistics, 16(2-3), 213-229. 
Dubois, B., Slachevsky, A., Litvan, I., \& Pillon, B. (2000). The FAB: A Frontal Assessment Battery at bedside. Neurology, 55(11), 1621-1626.

Edwards, S. (2005). Fluent aphasia. Cambridge, UK: Cambridge University Press.

Ehrensperger, M. M., Berres, M., Taylor, K. I., \& Monsch, A. U. (2010). Early detection of Alzheimer's disease with a total score of the German CERAD. Journal of the International Neuropsychological Society, 16(5), 910-920.

Faroqi-Shah, Y. (2007). Are regular and irregular verbs dissociated in non-fluent aphasia? A meta-analysis. Brain Research Bulletin, 74(1-3), 1-13.

Faroqi-Shah, Y., \& Friedman, L. (2015). Production of verb tense in agrammatic aphasia: A meta-analysis and further data. Behavioural Neurology, 2015(1), 1-15.

Faroqi-Shah, Y., \& Thompson, C. K. (2003). Regular and irregular verb inflections in agrammatism: Dissociation or association? Brain and Language, 87(1), 9-10.

Faroqi-Shah, Y., \& Thompson, C. K. (2004). Semantic, lexical, and phonological influences on the production of verb inflections in agrammatic aphasia. Brain and Language, 89(3), 484-498.

Faroqi-Shah, Y., \& Thompson, C. K. (2007). Verb inflections in agrammatic aphasia: Encoding of tense features. Journal of Memory and Language, 56(1), 129-151.

Howard, D., \& Patterson, K. (1992). The Pyramids and Palm Trees Test: A test for semantic access from words and pictures. Bury St. Edmunds, UK: Thames Valley Test Company.

Huber, W., Poeck, K., Weniger, D., \& Willmes, K. (1983). Aachener Aphasie-Test (AAT). Göttingen, Germany: Hogrefe-Verlag.

Kok, P., van Doorn, A., \& Kolk, H. (2007). Inflection and computational load in agrammatic speech. Brain and Language, 102(3), 273-283.

Levelt, W. M. J. (1989). Speaking: From intention to articulation. Cambridge, UK: Cambridge University Press.

Longworth, C. E., Keenan, S. E., Barker, R. A., Marslen-Wilson, W. D., \& Tyler, L. K. (2005). The basal ganglia and rule-governed language use: Evidence from vascular and degenerative conditions. Brain, 128(3), 584-596.

Macoir, J., Fossard, M., Mérette, C., Langlois, M., Chantal, S., \& Auclair-Ouellet, N. (2013). The role of basal ganglia in language production: Evidence from Parkinson's disease. Journal of Parkinson's Disease, 3(3), 393-397.

Martin, N., \& Reilly, J. (2012). Short-term/working memory impairments in aphasia: Data, models, and their application to aphasia rehabilitation. Aphasiology, 26(3-4), 253-257.

Murray, L. L., \& Ramage, A. E. (2000). Assessing the executive function abilities of adults with neurogenic communication disorders. Seminars in Speech and Language, 21(2), 153-168.

Nasreddine, Z. S., Phillips, N. A., Bédirian, V., Charbonneau, S., Whitehead, V., Collin, I., ... Chertkow, H. (2005). The Montreal Cognitive Assessment, MoCA: A brief screening tool for mild cognitive impairment. Journal of the American Geriatrics Society, 53(4), 695-699.

Penke, M., Janssen, U., Indefrey, P., \& Seitz, R. (2005). No evidence for a rule/procedural deficit in German patients with Parkinson's disease. Brain and Language, 95(1), 139-140.

Richter, K., Wittler, M., \& Hielscher-Fasabend, M. (2006). BIAS: Bielfelder Aphasie Screening zur Diagnostik akuter Aphasien. Hofheim, Germany: NAT-Verlag.

Ullman, M. T. (2001). A neurocognitive perspective on language: The declarative/procedural model. Nature Reviews Neuroscience, 2(10), 717-726.

Wechsler, D. (1987). Wechsler Memory Scale-Revised. San Antonio, TX: The Psychological Corporation. 